Discussion Paper No. 10-047

\title{
School Entrance Recommendation: A Question of Age or Development?
}

Julia Horstschräer and Grit Muehler

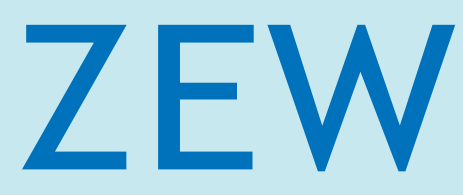

Zentrum für Europäische Wirtschaftsforschung $\mathrm{GmbH}$

Centre for European

Economic Research 
Discussion Paper No. 10-047

\title{
School Entrance Recommendation: A Question of Age or Development?
}

\author{
Julia Horstschräer and Grit Muehler
}

Download this ZEW Discussion Paper from our ftp server:

ftp://ftp.zew.de/pub/zew-docs/dp/dp10047.pdf

Die Discussion Papers dienen einer möglichst schnellen Verbreitung von neueren Forschungsarbeiten des ZEW. Die Beiträge liegen in alleiniger Verantwortung der Autoren und stellen nicht notwendigerweise die Meinung des ZEW dar.

Discussion Papers are intended to make results of ZEW research promptly available to other economists in order to encourage discussion and suggestions for revisions. The authors are solely responsible for the contents which do not necessarily represent the opinion of the ZEW. 


\section{Non-technical summary}

According to school entry regulations in most countries, the composition of school entrance cohorts is determined by a fixed cutoff date. This procedure creates inter-cohort differences in age and development since some of the children entering school have just turned six whereas others are almost seven. The differences in age and developmental status translate into differences in school performance which persist over almost the whole period of compulsory schooling. Although diminishing during secondary school, these effects might influence decisions like school entry and track choice. This might be particularly important in a system of early tracking as it is the case in Germany.

Developmental disparities become visible for the first time when the school entrance decision is made. All German federal states rely on medical screenings of the school entering cohort as a form of compulsory health examination and to assure a minimum developmental level for school start. The German school entrance screenings are administered by government pediatricians. They thoroughly examine the health status of the children and perform tests on pre-academic skills such as cognitive development, social behavior or motor skills. At the end, the pediatrician decides whether to recommend the child to start compulsory primary schooling.

This paper addresses the question of how early differences in age and development influence children's probability of being recommended for school and assesses whether developmental gaps close by delaying school entry. We use a unique administrative data set on the school entrance examination of all children in the German federal state of Brandenburg. Our results show that impairments in cognitive, socio-emotional and motor development as well as health are negatively related to the probability to receive a school recommendation. Moreover, younger children are less likely to be recommended for school. This occurs for two reasons: First, they show developmental impairments more often. Second, they have a lower probability of being recommended per se. Delaying school entry allows children to improve, although their developmental status remains below average. Especially the younger retained children catch-up more often.

While cutoff rules determine school entry by age, entrance examinations consider also a child's developmental status. By not recommending younger and developmentally disordered children the examination sets a minimum development requirement for school entry and harmonizes the school entering cohort with respect to age and development. In general, flexible school entry rules that - besides age - also take childrens' development into account could mitigate disadvantages for relatively young children. 


\section{Das Wichtigste in Kürze}

In Deutschland gilt die gesetzliche Schulpflicht für Kinder mit Erreichen des sechsten Lebensjahres. Die Einschulung gemäß dem feststehenden Stichtag im August oder September führt jedoch dazu, dass manche Erstklässler gerade erst sechs Jahre alt sind, wohingegen andere bald schon sieben Jahre alt werden. Diese Unterschiede im Alter zeigen sich auch in der Entwicklung der Kinder, so dass ältere Kinder in Tests und Klassenarbeiten im Durchschnitt bessere Ergebnisse zeigen, als ihre jüngeren Klassenkameraden.

Obwohl sich diese Entwicklungsunterschiede nach der Grundschule verringern, können sie dennoch den Bildungsverlauf entscheidend beeinflussen. Dies gilt insbesondere für Deutschland, wo sehr früh darüber entschieden wird, welche weiterführende Schule ein Kind besucht. Eine Möglichkeit, Entwicklungsunterschiede früh zu erkennen, bietet die Schuleingangsuntersuchung, die deutschlandweit im Jahr der Einschulung durchgeführt wird. Obwohl sie primär der Gesundheitsberichterstattung dient, wird aus den Ergebnissen der Entwicklungsdiagnostik auch eine Empfehlung für die Einschulung abgeleitet. Der untersuchende Arzt kann empfehlen, Kinder mit Defiziten in der kognitiven, sozioemotionalen oder motorischen Entwicklung ein Jahr vom Schulbesuch zurückzustellen.

Dieses Papier untersucht den Einfluss des Alters und des Entwicklungsstandes auf die Wahrscheinlichkeit, für die Schule empfohlen zu werden, und wie sich eine Zurückstellung auf den Entwicklungsstand auswirkt. Für die Analysen werden die Daten der Schuleingangsuntersuchung des Bundeslandes Brandenburg genutzt. Die Ergebnisse zeigen, dass Defizite in der kognitiven, sozio-emotionalen oder motorischen Entwicklung sowie gesundheitliche Einschränkungen die Wahrscheinlichkeit senken, eine Einschulungsempfehlung zu erhalten. Darüber hinaus werden jüngere Kinder häufiger vom Schulbesuch zurück gestellt. Gleichzeitig holen sie aber stärker auf als vergleichbare ältere Kinder. Nichtsdestotrotz weisen nicht empfohlene Kinder auch im Folgejahr noch immer überdurchschnittlich häufig Entwicklungsrückstände auf.

Während bei einer stichtagsgebundenen Einschulungsregelung lediglich das Alter der Kinder maßgeblich ist, berücksichtigt eine zusätzlich durchgeführte Schuleingangsuntersuchung auch deren Entwicklungsstand. Durch die Zurückstellung von jüngeren Kindern und solchen mit Entwicklungsauffälligkeiten trägt die Schuleingangsuntersuchung dazu bei, Alters- und Entwicklungsunterschiede auszugleichen. Generell könnten weniger strikte Einschulungsregeln - die neben dem Alter auch den Entwicklungsstand berücksichtigen - dazu beitragen, Nachteile besonders für junge Kinder zu verringern. 


\title{
School Entrance Recommendation: A question of age or development?
}

\author{
Julia Horstschräer and Grit Muehler \\ ZEW, Mannheim*
}

July 19, 2010

\begin{abstract}
According to school entry regulations in most countries, the composition of school entrance cohorts is determined by a fixed cutoff date. This procedure creates inter-cohort differences in age and development which can severely influence educational trajectories. Developmental examinations at school entry might be an instrument to mitigate these differences by delaying school entry for children with developmental impairments. Using data on the compulsory school entrance screening in the German federal state of Brandenburg, this paper shows that age and developmental status are the major influencing factors for a child's probability to receive a school recommendation. Younger children and children with impairments in cognitive, socio-emotional and motor development as well as health are less likely to be recommended. Delaying school entry allows them to improve, although their developmental status remains below average. School entrance examinations thus allow for some harmonization of school cohorts with respect to age and developmental differences.
\end{abstract}

Keywords: child development, school entrance, school recommendation, relative age JEL-classification: J13, I21, I38

Acknowledgements: This work uses administrative data from the school entrance examination in the German federal state of Brandenburg. We thank the health ministry of Brandenburg for the provision of the data, in particular Andreas Böhm and Gabriele Ellsäßer from the federal health office for their generous support and cooperation. We are also grateful to Maresa Sprietsma, Katja Coneus, Andrea Mühlenweg and Bernd Fitzenberger for helpful comments and discussion. All remaining errors are ours.

\footnotetext{
*Centre for European Economic Research (ZEW), P.O. Box 103443, D-68034 Mannheim, Germany, Julia Horstschräer: hortschraeer@zew.de, Grit Muehler: muehler@zew.de.
} 


\section{Introduction}

At first glance, grouping children who have reached compulsory school age (e.g. six years) at a fixed entry date seems to create an age-homogeneous cohort: six year old children are put together in one classroom. But a closer look reveals that they are not of the same age. Some of them just turned six whereas others are almost seven. The age range is additionally widened if entry regulations are not binding. Parents may be allowed to circumvent the policy either by sending their children earlier to school or by holding them back for a year. These absolute age gaps created by the school entry regulation are related to differences in development. Moreover, once in school, they result in differences in school performance e.g. at tests or exams (Crawford et al. 2007, Datar 2006). Developmental examinations before school entry might be a useful instrument to screen the developmental status of children. They allow the detection of impairments early on and the retention of school entry if necessary. This paper explores how early gaps in absolute age and in developmental status influence a child's probability to be recommended for school and whether developmental gaps close by delaying school entry.

The literature on school entry age states that the inter-cohort variation in age and developmental status translates into differences in school performance which persist over almost the whole period of compulsory schooling (Bedard \& Dhuey 2006, Puhani \& Mühlenweg 2010). Although grouped by (year of) age, relatively young children who take the exams together with their older classmates perform worse. This difference in performance can be attributed to the (month) difference in age and thus to development (Crawford et al. 2007). Developmental inequalities established in the school entrance cohort seem to be reinforced (or at least not attenuated) during primary school (Datar 2006) and tend to fade away during secondary school (Elder \& Lubotsky 2009). Even if they diminish over time, parents and - in our particular case pediatricians - decide about school entrance based on these developmental outcomes. Thereby, they potentially influence educational trajectories such as track choice or timing of labor market entry as children are younger or older when these decisions are taken.

All German federal states rely on medical screenings of the school entering cohort to assure a minimum developmental level for school start. Internationally, the use of routine or selective assessments at school entry is mixed. They often focus on school readiness but can also include health (see e.g. for Canada Doherty et al. 2002, p. 75 or for the U.S. Garber et al. 2007, Stedron 2009). The German school entrance screenings are administered by government pediatricians. They thoroughly examine the health status of the children and perform tests on pre-academic skills such as cognitive development, social behavior or motor skills. At the end, the pediatrician decides whether to recommend the child to start compulsory primary schooling. 
For our study, we use a unique administrative data set on the school entrance examination of all children in the school entrance cohorts 2006 and 2007 in the German federal state of Brandenburg. Our results show that age and developmental status are important predictors for school recommendation. Impairments in cognitive, socio-emotional and motor development as well as health are negatively related to the probability to receive a school recommendation. Moreover, younger children are less likely to be recommended for school even when developmental status is controlled. This result is of particular importance to the children who are born in months close to the cutoff month. As they are always the youngest they are systematically more likely to be held back for one year. Delaying school entry allows children to improve, although their developmental status remains below average. Especially the younger retained children catch up more often. This might be easier for them as a smaller fraction of non-recommended younger children shows development impairments in the first place. Pediatricians might either anticipate the improvement of younger children or might want to place them into a more favorable age position in the cohort of the following year.

The paper contributes to the literature on school entry age and birth month effects by showing that developmental heterogeneity caused by differences in age is important early on. Moreover, we explore the endogeneity issue this literature addresses by analyzing the school entry decision in detail. A school entry examination provides a means to mitigate developmental heterogeneity but cannot balance the strong age inequality created by the fixed school entry regulation. However, performance differences in school as described in the literature on school entry age could be attenuated by a entrance screening.

The paper is structured as follows. The next section gives some background information on the school entry examination. The estimation strategy is presented in Section 3, followed by the results in Section 4 and Section 5 concludes.

\section{Data}

In Germany, schooling becomes compulsory in the calendar year in which a child turns six years old. The cut-off dates vary between federal states. In the federal state of Brandenburg the cut-off date is September, 30th each year. For children born after that date ("Kann-Kinder"), i.e. children who turn six in the last three months of the year, parents can decide whether their child should start school the same year or the following year. We refer to these children as "early attendees" if they attended the examination in the same year.

All children who reach compulsory school age or shall enter school early have to attend the school entrance examination. This is a medical examination which is taken from 
Figure 1: Structure of school entrance cohorts

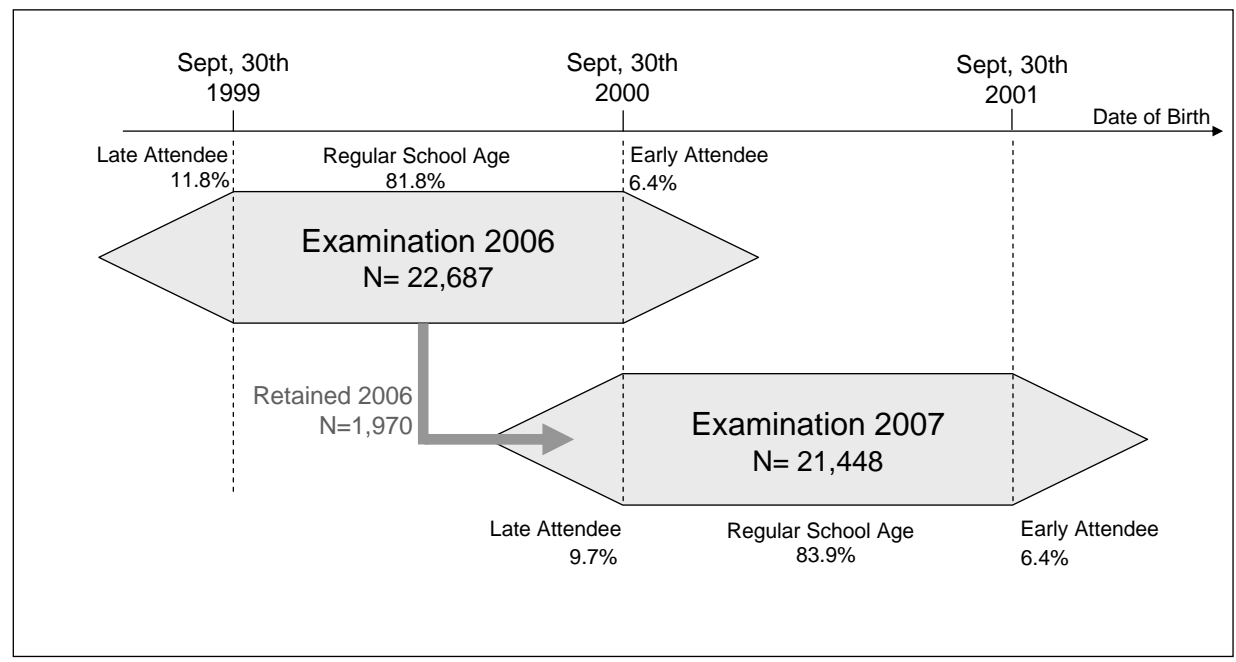

Data Source: Health Ministry of Brandenburg 2006, own calculations.

January to May the year they enter school. It serves as a check-up for age adequate physical and psychological development. The examination is administered on the county level by government pediatricians according to standards set by the ministry of health in Brandenburg. It is a mandatory medical screening of all children as they may not have been presented to their family pediatrician for any of the preventive voluntary routine check-ups for babies and infants. If the child shows developmental impairments, parents get advice for further medical treatment and a controlling scheme is implemented (Landesgesundheitsamt Brandenburg 2008). At the end of the examination the pediatrician decides whether to recommend the child for school. This recommendation is not binding for the parents.

Our data include all children participating in the school entrance examinations in Brandenburg in the years 2006 and 2007 (see Figure 1). As participation in the screening is mandatory for all children in a cohort, the results can serve as a representative overview on the status of the population of school starters in the state of Brandenburg in the respective year. Only a few German states use standard testing procedures which are regulated at a federal level, so comparable data and comprehensive reports are scarce (see e.g. the report of Landesinstitut für Gesundheit und Arbeit des Landes NordrheinWestfalen 2008 for the German state of North Rhine-Westphalia). To our knowledge, only one other economic study uses data of a school entrance examination and analyzes the impact of health on cognitive and language abilities (Salm \& Schunk 2008). But similar to most epidemiological studies (e.g. Mayr 1990), the authors rely on data from a local health authority and thus on a much smaller data set.

Children who reach compulsory school age by the end of September 2006 or September 2007 have to attend the school entrance examination in 2006 or 2007, respectively. Figure 1 explains the structure of our data. For the year 2006, we have data on 22,755 
Figure 2: Screening dimensions

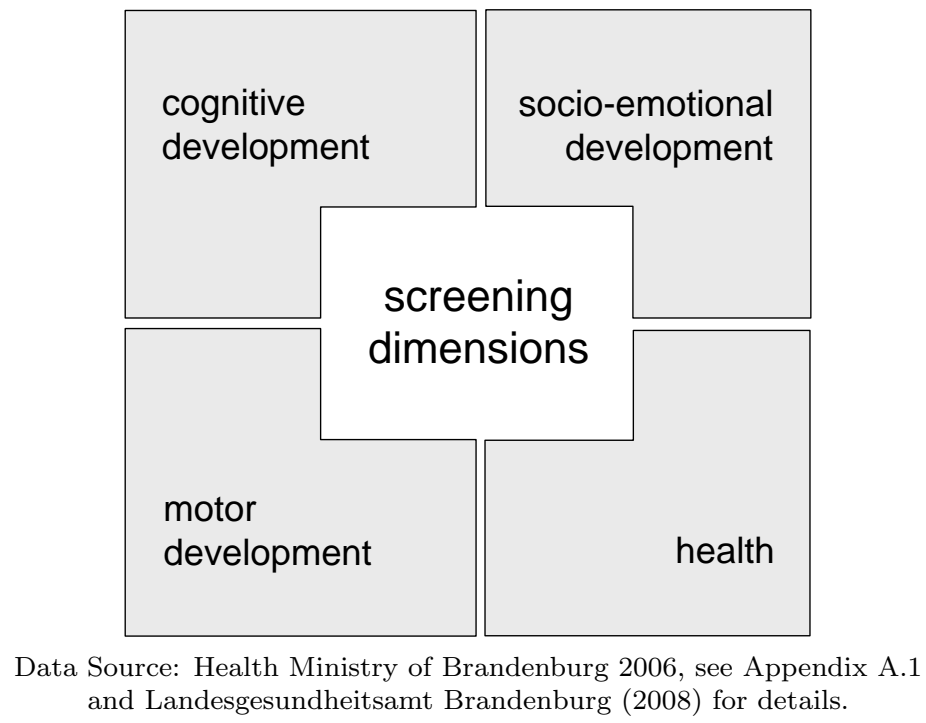

children who attend the school entrance examination. We have to drop 68 observations $(0.3 \%)$ because of not having information on the recommendation for school or the date of birth. In the following year 21,504 children attended the examination and $56(0.3 \%)$ were dropped because of missing information on the same variables. Our estimation sample thus consists of 22,687 observations for 2006 and 21,448 observations in 2007.

The children who reach compulsory school age in year 2006 are born between October 1st, 1999 and September 30th, 2000. Children attending the examination in the following year, i.e. 2007, reach compulsory school age when born between October 1st, 2000 and September 30th, 2001. If the children are born later, they can be examined early if the parents want them to start school before reaching compulsory school age. This applies to about $6.4 \%$ of all children in both years. In contrast, some of the children in our samples are above compulsory school age, namely 11.8\% in 2006 and 9.7\% in 2007 (see Figure 1). Most of them (93\% in 2006, $94 \%$ in 2007) were not recommended the year before and attend the entrance exam a second time. 1,970 children were retained in 2006 and examined a second time in 2007. We use this sample of children for our analysis on the development of retained children presented in Sections 3.2 and 4.2.

The school entrance examination in Brandenburg is based on a core set of indictors of the International Classification of Functioning, Disability and Health (ICF) developed by the World Health Organization (Üstün et al. 2003, Simeonsson et al. 2003). ${ }^{1}$ Our indicator of interest is developmental status in four screening dimensions: cognitive abilities, socioemotional wellbeing, motor skills and health (see Figure 2). As these indicators are not measured on continuous scales, we use binary variables for each of the dimensions which

\footnotetext{
${ }^{1}$ The main purpose of the examination and the classification itself is to document the health status of a population. The framework describes health using body (functioning and structure), person (activity, execution of tasks) and social level (participation, involvement in a life situation) as main domains.
} 
indicate whether a child shows developmental impairments in this dimension or not. All indicators in the four dimensions depend on several sub-tests and on the clinical judgment of the physician. ${ }^{2}$

Our outcome variable is the school entrance recommendation. The recommendation is a condensed assessment given based on the pediatrician's own observations, a questionnaire completed by the parents and the results of the standardized assessments for developmental status and health. The medical assessment covers a set of core categories to describe body functions such as seeing and hearing, musculoskeletal functions or functions of the respiratory system. Furthermore, questions on parental education, their labor market participation and immigration background as well as questions on the child's behavior at home and in kindergarten give some information on home and family environment. See Appendix A.1 and Landesgesundheitsamt Brandenburg (2008) for a detailed description of the tests used to assess the developmental status and the information obtained from the parents.

\section{Estimation strategy}

To assess the importance of school entrance examinations for detecting and mitigating early performance differences, we are interested in two questions. The first is, how early gaps in age and development influence children's probability to be recommended for school. The second is, whether developmental gaps close by delaying school entry. In the following we explain the estimation strategies to answer these questions.

\subsection{Determinants of school entrance recommendation}

To answer the first question, we use the school recommendation as dependent variable. The indicator variable $R e c_{i}$ becomes 1 if the child $i$ is recommended to start primary school in the year of the examination and 0 otherwise. The underlying estimation equation is displayed in Equation 1 and estimated using a probit model.

$$
\operatorname{Rec}_{i}^{*}=\beta_{0}+\beta_{1} A g e_{i}+\beta_{2} D E V_{i}+\beta_{3} C_{i}+\beta_{4} F_{i}+\beta_{5} M_{i}+u_{i}
$$

The main variables of interest are age $\left(A g e_{i}\right)$ and a vector of our four developmental status variables $\left(D E V_{i}\right)$. Age is measured in months at the time of the entrance examination.

\footnotetext{
${ }^{2}$ The pediatricians are given detailed and comprehensive information on all parts of the examination by a handbook. This is constantly updated and regular quality meetings are held to reinforce the standards set by the ministry of health in Brandenburg. Although most pediatricians commit to these standards, the data show that not all of them deduce their diagnosis from the sub-tests. We therefore consider both ways to classify developmental impairments. See Appendix A.1 for details on the sub-tests.
} 
The binary development indicators pick up impairments in each of the four domains as described in the previous section and Appendix A.1.

Furthermore, we sequentially include interaction terms between the developmental indicators and age separately for each dimension as shown in Equation 2. These terms capture the joint effect of age and development on recommendation and thereby indicate heterogenous effects of the development status with respect to age.

$$
\operatorname{Rec}_{i}^{*}=\beta_{0}+\beta_{1} A_{g e_{i}}+\beta_{2} D E V_{i}+\beta_{3} D E V_{i} \times A g e_{i}+\beta_{4} C_{i}+\beta_{5} F_{i}+\beta_{6} M_{i}+u_{i}
$$

Control variables for both equations include a vector of child $\left(C_{i}\right)$ and family $\left(F_{i}\right)$ background variables as well as dummies for the month of examination $\left(M_{i}\right)$. Background information on the child $\left(C_{i}\right)$ includes gender, birth weight, non-German mother tongue and attendance of institutional child care. We also include age threshold variables for children below (early attendee) and above compulsory school age (late attendee). Family background variables $\left(F_{i}\right)$ provided by the parents are parental education, their labor market participation, immigration background, family type and the number of siblings. Parental education and labor market participation are collapsed into a variable capturing the socio-economic status (SES) for both parents (Böhm et al. 2007). ${ }^{3}$ Dummies for the month of examination $\left(M_{i}\right)$ are included to control for the length of the period until school entry. ${ }^{4}$ As development of children in this age group might change within a few months, pediatricians could possibly recommend children more "generously" in the early months of the examination period, e.g. January and February as there is still some time left for improvements until school entrance in September.

\subsection{Development of retained children}

To analyze whether the performance differences in school are mitigated by retaining, we exploit the fact that some children repeat the examination. Children, who are not recommended to school in 2006 spend an additional year in kindergarten and attend the school entrance examination again in the following year. As early child development is

\footnotetext{
${ }^{3}$ We use the SES-classification provided and published by the federal health Office of Brandenburg (Böhm et al. 2007). Parents are classified into high socio-economic status if both have a high-school diploma (more than 10 years of compulsory school education) and at least one of them is full-time employed. In case of missing values or single parenthood, the characteristics of the remaining parent are also assigned to the second parent. We include dummy variables for single parenthood and missing values in our regression. Results do not change when using education and labor market participation of the mother instead of the predefined socio-economic status.

${ }^{4}$ The examination is predominantly taken from January to May, however there are very few children tested in the months June to December. The control variable for month January thus includes also the months October, November, December. The variable for month May includes also the months June, July, August and September. Reference category is March as this is the month where most examinations are taken.
} 
very heterogenous and tightly depends on age, developmental impairments might not be persistent and children might catch-up. Furthermore, the pediatricians are advised to recommend further treatment to the parents of children who were diagnosed with developmental impairments (Landesgesundheitsamt Brandenburg 2008). Therefore, we expect that they improve during the one year delay.

Unfortunately the data do not allow the tracking of children over time. But using the data of 2006 and 2007, we observe the non-recommended children of 2006 again as repeaters of the examination in 2007. As the school recommendation is not binding, we observe 1,970 non-recommended children in 2006 and 2,316 repeaters in $2007 . .^{5}$ We are interested in the development of the non-recommended children, so we restrict the 2007 sample to the repeaters which we most likely already observe in 2006 and then compare the development status of the non-recommended children in 2006 with the adjusted group of repeaters in 2007.

In order to identify the repeaters in 2007 who were most likely not recommended in 2006 we employ propensity score matching without replacement to match an observation of 2006 to its first nearest neighbor in 2007 (which is ideally the same child) according to its characteristics. We exclude the 346 repeater observations of 2007 which were not identified as nearest neighbors and thus are left with 1,970 non-recommended children in 2006 and 1,970 repeating children in 2007. By matching these groups contain most likely the same children. In the following, we refer to this subsample of repeating children in 2007 as the group of repeaters. The characteristics of the 1,970 non-recommended children in 2006 and the original 2,316 repeaters in 2007 are largely overlapping so that we can assure common support (see Figure A.2.1 in the Appendix). We only match on characteristics of the child and the parents which we expect constant over time (gender, birth month and year, birth weight, non-German mother tongue, maternal school education, single parenthood and siblings) and obtain a sample which is largely balanced (see Table A.2.2 in the Appendix for t-test on the differences in characteristics for retainers and repeaters). Our sample for 2007 contains after the matching 21,102 observations and is thus by the 346 observations smaller since these do not have a non-recommended counterpart in 2006. We use this adjusted data set to analyze the development of retained children in more detail.

By comparing the probability for developmental impairments at the two examinations the repeating children attend we can describe the development of the retained children during the one year school delay. This is done by pooling the matched cross-sections of the examinations in 2006 and 2007. Hence, the data contains all children examined in 2006 and 2007 apart from the 346 repeating children in 2007 who are not a nearest

\footnotetext{
${ }^{5}$ The addition of 346 children is caused by parents who hold back their children although they have been recommended.
} 
neighbor to a non-recommended child in 2006. In this sample we define dummy variables indicating that a child was non-recommended in $2006\left(\right.$ NonRecO6 $\left._{i}\right)$ and is a repeater in

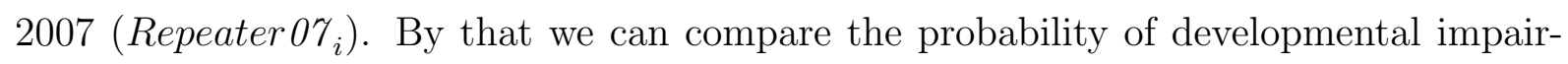
ments for children at the time they are not recommended with the developmental status of their matched counterparts one year later. The estimation equation reads as following:

$$
\begin{aligned}
D E V_{i}^{*}=\beta_{0} & +\beta_{1} \text { NonRec06 }_{i}+\beta_{2} \text { Repeater07 }_{i} \\
& +\beta_{3} \text { Repeater06 }_{i}+\beta_{4} \text { NonRec07 }_{i}+\beta_{5} \text { Year07 } \\
& +\beta_{6} C_{i}+\beta_{7} F_{i}+\beta_{8} M_{i}+u_{i}
\end{aligned}
$$

Our outcome variable is the probability of showing an impairment in one of the four developmental dimensions $D E V_{i}$. In addition to the indicators for non-recommended in 2006 (NonRec06 $i$ ) and repeater in 2007 (Repeater ${ }^{r_{i}}{ }_{i}$ ), we include dummy variables for being repeater in 2006 (Repeater 06 $6_{i}$ ), non-recommended in 2007 (NonRec0\% ${ }_{i}$ ) and a year dummy for 2007 (Year0\%) to ensure that we always refer to the same group of children as the reference group. Moreover, the same child $\left(C_{i}\right)$, family $\left(F_{i}\right)$ and month of examination $\left(M_{i}\right)$ control variables as in Equation 1 are included in the estimation. Hence, the probability of showing a development impairment is calculated in reference to nonrepeating, recommended children of 2006 with similar child and family characteristics. The average partial effects on the two dummy variables of interest $\left(\right.$ NonRec06 $_{i}$ and Repeater $07_{i}$ ) are calculated only for the children belonging to the group of repeaters, i.e. as average treatment effect on the treated. The difference between the partial effects of the two groups can be interpreted as the reduction in the share of children with developmental impairments which is achieved by delaying school entry.

\section{Results}

The results of our analysis regarding the two research questions are discussed in the following. In Section 4.1 we present the estimations regarding the determinants of a school entrance recommendation and Section 4.2 focuses on the retained children and whether they improve with respect to their developmental status by delaying school entry.

\subsection{Determinants of school entrance recommendation}

Before estimating the determinants of receiving a recommendation for school, we first gain insight by comparing the characteristics of recommended and non-recommended children. At the 2006 examination $90.5 \%$ (20,717) of the children are recommended for school. Table 
1 shows the differences between the recommended and non-recommended children with regard to child characteristics, developmental impairments and parental background. ${ }^{6}$

Table 1: Means of recommended vs. non-recommended children in 2006 (\%)

\begin{tabular}{lrr}
\hline & Recommended & Non-recommended \\
\hline Child & & \\
Female & 0.48 & 0.36 \\
Age (in months) & 72.02 & 67.49 \\
Non-German mother tongue & 0.02 & 0.03 \\
Birth Weight (in kg) & 3.39 & 3.23 \\
Child care $>$ 3 years & 0.70 & 0.49 \\
Early attendee & 0.05 & 0.18 \\
Late attendee & 0.13 & 0.00 \\
Developmental Impairments & & \\
Cognitive development & 0.11 & 0.50 \\
Socio-emotional development & 0.08 & 0.34 \\
Motor development & 0.12 & 0.44 \\
Health & 0.39 & 0.52 \\
Family Background & & \\
Low SES & 0.18 & 0.32 \\
Medium SES & 0.55 & 0.51 \\
High SES & 0.26 & 0.17 \\
Single Parent & 0.17 & 0.21 \\
Siblings & 0.66 & 0.68 \\
\hline$N$ & 20,717 & 1,970 \\
\hline Data Sor & & \\
\hline
\end{tabular}

Data Source: Health Ministry of Brandenburg 2006, own calculations. The number of observations is the total number without considering missings. The following variables have missing values: NonGerman mother tongue, birth weight, child care, social status, single parent and number of siblings. The maximum share of missing values amounts to $3.9 \%$ for the recommended and $6.7 \%$ for the nonrecommended children. T-Tests on the group means are performed. All differences are significant at the $1 \%$ level, except the difference for non-German mother tongue (not significant) and siblings (significant at the $10 \%$ level).

The comparison shows that the recommended and non-recommended children differ substantially, especially with regard to the measures of developmental status and health. In the recommended cohort, fewer children show impairments in cognitive, socio-emotional or motor development. Most of the children affected by cognitive impairments are diagnosed with developmental disorders in language and only very few (only $2 \%$ out of the $11 \%$ of the non-recommended children) show deficits in intelligence (see Appendix A.1 for the tested domains). Disorders in socio-emotional development comprise anxiety, anti-social (i.e. aggressive) behavior, enuresis and Attention Deficit/Hyperactivity Disorder (ADHD). $3 \%$ of the recommended and $11 \%$ of the non-recommended children are diagnosed with

\footnotetext{
${ }^{6}$ For the full sample of 2007 , the recommendation rate is $91.1 \%(19,535)$. The analysis of group means yields similar results as for 2006. Some of the variables have a small amount of missing values, see tablenotes of Table 1 . The regressions include dummies for missing values.
} 
ADHD. The prevalence rates in all four dimensions are in line with results from other developmental studies (Mayr 1990) and the school entrance screenings in other federal states in Germany (Landesinstitut für Gesundheit und Arbeit des Landes Nordrhein-Westfalen 2008).

The comparison shows further that recommended children are more frequently girls, are older, have had a higher birth weight and longer child care experience. Children above compulsory school age ("late attendees") are solely among the recommended children. Children with a low social status are less often recommended to start school. They do not differ much with regard to the presence of siblings or living in a single-parent household. The multivariate probit regression as introduced in Equation 1 confirms the results of the mean comparison. Table 2 reports the results of this regression when sequentially changing the specification. The marginal effects presented in the table are average partial effects, i.e. we calculated the individual probability for each observation and then averaged over all observations.

The results presented in the first column reveal that there is a substantial positive influence of age. Each month the child is older when attending the examination raises the probability of being recommended for school by 2.0 percentage points. The other socioeconomic background and child variables are related to the probability to receive a school recommendation, albeit to a low extent. Average partial effects of the controls are reported in Table A.2.1 in the Appendix. Being female, birth weight, child care experience and high socio-economic status of the parents are positively related to school recommendation. Furthermore, both early and late attendees are more likely to be recommended for school. For late attendees, this result indicates that not recommending children for school might not be an option once they are older than their peers. For early attendees this seems plausible as well, as they might be a very selective group with characteristics which are not entirely captured by the parental control variables. ${ }^{7}$

\footnotetext{
${ }^{7}$ As a robustness check we estimated the equations on a sample of 18,551 children, excluding early and late attendees. These estimations yields similar results for all covariates, e.g. the age effect is between 1.7 and 1.9 percentage points depending on the specification.
} 
Table 2: Probit regression of school recommendation on age, developmental status and interaction terms (2006)

\begin{tabular}{|c|c|c|c|c|c|c|}
\hline & \multicolumn{6}{|c|}{ Average partial effects } \\
\hline & (I) & (II) & (III) & $(\mathrm{IV})$ & $(\mathrm{V})$ & $(\mathrm{VI})$ \\
\hline Age (in months) & $0.020^{* * *}$ & $0.016^{* * *}$ & $0.016^{* * *}$ & $0.015^{* * *}$ & $0.016^{* * *}$ & $0.016^{* * *}$ \\
\hline \multicolumn{7}{|l|}{ Development } \\
\hline Cognitive & & $-0.156^{* * *}$ & -0.236 & $-0.158^{* * *}$ & $-0.156^{* * *}$ & $-0.156^{* * *}$ \\
\hline Socio-emotional & & $-0.102^{* * *}$ & $-0.102^{* * *}$ & $-0.871^{* * *}$ & $-0.102^{* * *}$ & $-0.102^{* * *}$ \\
\hline Motor & & $-0.068^{* * *}$ & $-0.068 * * *$ & $-0.068^{* * *}$ & -0.106 & $-0.068^{* * *}$ \\
\hline Health & & $-0.009^{* * *}$ & $-0.009 * * *$ & $-0.009^{* * *}$ & $-0.009 * * *$ & -0.027 \\
\hline \multicolumn{7}{|l|}{ Interaction terms } \\
\hline Cognitive $\times$ age & & & $0.022^{* * *}$ & & & \\
\hline Soc.-em. $\times$ age & & & & $0.023^{* * *}$ & & \\
\hline Motor $\times$ age & & & & & $0.011^{* * *}$ & \\
\hline Health $\times$ age & & & & & & $0.002^{*}$ \\
\hline Child controls & \multicolumn{6}{|c|}{ yes } \\
\hline Family background & \multicolumn{6}{|c|}{ yes } \\
\hline Month of examination & \multicolumn{6}{|c|}{ yes } \\
\hline Missing dummies & \multicolumn{6}{|c|}{ yes } \\
\hline Pseudo $-R^{2}$ & 0.2268 & 0.3778 & 0.3778 & 0.3811 & 0.3778 & 0.3778 \\
\hline$N$ & \multicolumn{6}{|c|}{ 22, 687} \\
\hline
\end{tabular}

Data Source: Health Ministry of Brandenburg 2006, own calculations. * $/ * * / * * *$ indicate significance at the 10/5/1 percent level. Child controls include variables female, non-German mother tongue, birth weight, child care duration longer than 3 years as well as dummies for early and late attendees. Control variables on family background include dummies for socio-economic status, single parenthood and siblings living in the household. The month of examination is controlled for by dummy variables. Missing dummies are included to indicate observations with missing values in one of the variables. Missings are set to zero (dummy variables) or to the mean (continuous variables) and included in the regression. The marginal effects for the control variables are presented in Table A.2.1 in the Appendix.

Including the four variables for developmental status into the regression shows that they significantly influence the probability to be recommended. In particular cognitive and socio-emotional development seem to be important for school recommendation. Compared to the reference group of mean age children with the same background and without impairments in the four dimensions, showing e.g. cognitive impairments reduces the probability to be recommended to school by 15.6 percentage points. Although slightly decreasing, the age effect persists when controlling for developmental status. Age increases, ceteris paribus, the probability of school recommendation by 1.6 percentage points per month. Thus, an age difference of 12 months would result in a larger impact than showing an impairment in cognitive development.

Finally, we include interaction terms on age and developmental status to assess whether age affects children with and without developmental impairments differently. The results in the third column show the estimated marginal effects when including the same vari- 
Figure 3: Developmental status and age by month of birth

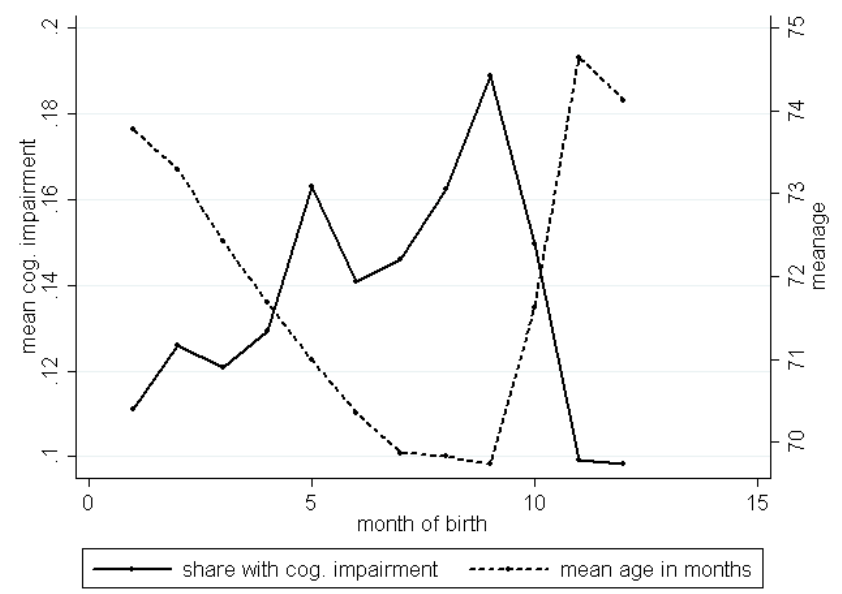

Data Source: Health Ministry of Brandenburg 2006, own calculations.

ables as before and adding an interaction term for cognitive impairment and age. ${ }^{8}$ Similar as in specification (II) the age effect for children without an impairment amounts to 1.6 percentage points. Taking the cognitive interaction term into account we can calculate that the age effect for children with a developmental disorder increases to 3.8 percentage points. ${ }^{9}$ Hence, for a child with a cognitive impairment each month of age raises the probability to get recommended much more than for the children without cognitive impairments. The age effect for a child with a socio-emotional disorder is similar (3.8 percentage points) while age plays a minor role for children with a motor (2.7 percentage points) or health (1.8 percentage points) disorder.

The influence of age is especially important for the children who are born in months close to the cut-off month set by federal state law. The beginning of compulsory schooling is regulated with a fixed cutoff date, which is September 30th in our case. Children who are born earlier in their cohort (e.g. in the fourth quarter of the year before they enter school) are older when passing the school entrance examination compared to children who are young in their cohort (i.e. born in the third quarter of the year they enter school). Figure 3 shows the inverse relationship between age (dashed line) and share of children diagnosed with cognitive impairments (solid line) by month of birth. ${ }^{10}$ The age at the school entry examination is constantly decreasing the closer a child's month of birth is before the school entry cutoff date at end of September. As seen, these children have a

\footnotetext{
${ }^{8}$ The marginal effects of the interaction terms are computed using the method introduced by Ai \& Norton (2003). Effect sizes and significance levels are similar to estimating all interaction effects together in a linear probability model with robust standard errors.

${ }^{9}$ In order to calculate this effect we need to sum the age effect for children without impairments (1.6 percentage points) and the age effect for children with an impairment as opposed to children without any developmental disorders (2.2 percentage points).

${ }^{10}$ The relationship holds also for the other developmental indicators (socio-emotional development, motor skills and health).
} 
Figure 4: Developmental status by month of age at examination

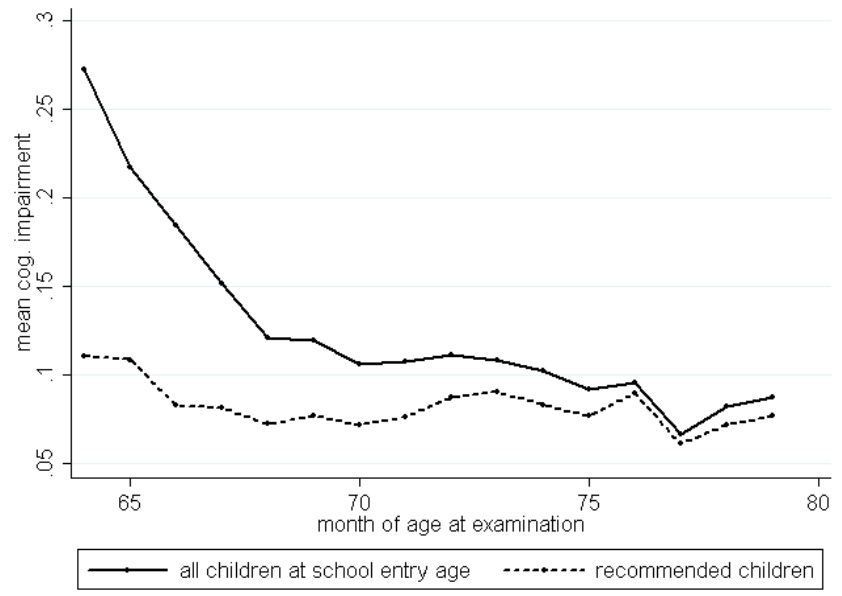

Data Source: Health Ministry of Brandenburg 2006, own calculations.

lower probability of being recommended for school because developmental disorders are more prevalent among the young children and because there is an additional negative impact of being young.

Moreover, comparing the sample of all children at school entry age to the group of recommended children visualizes the lower probability to receive a recommendation for young children with a higher share of cognitive impairments (Figure 4). Here, the solid line indicates the share of children showing a cognitive impairment within the group of all children at school entry age, compared to the share within the group of recommended children (dashed line) by age in months at the time of examination. In the full cohort, the share decreases by age whereas within the group of recommended children the share is almost equally distributed across age. ${ }^{11}$ The entrance screening thus reduces developmental heterogeneity between the children of the school entrance cohort.

To summarize the results of the first part, recommending children for school based on the results of a developmental screening procedure yields a school cohort with less developmental heterogeneity compared to a pure age-based entry regulation. The estimations of determining factors of the recommendation show that the pediatricians give their recommendation not only based on the child's development but also take the age of the child into account (see results in Table 2). Hence, the examination can be seen as a minimum hurdle which creates a slightly more homogeneous school entry cohort than the group of children in the entry age. Our result also describe one possible endogeneity issue the literature on school entry age (e.g. Puhani \& Mühlenweg 2010) addresses. We show that performance differences in school due to fix cutoff rules as described by this literature can

\footnotetext{
${ }^{11}$ We observe this change in composition also with respect to the other developmental indicators (socioemotional development, motor skills and health).
} 
be mitigated by school entrance examinations, as the better developed and older children are more likely to receive a school recommendation.

\subsection{Development of retained children}

Having information on the school entrance examination in two subsequent years allows us to compare the developmental status and health of the retained children in the first examination in 2006 with the second examination in 2007. In this section, we use multivariate analysis to assess how much non-recommended children in 2006 deviate from non-repeating, recommended children of 2006 with respect to their development. Then we compare the developmental status of these children one year later (repeater 2007) to the same reference group and see whether the childrens' development improved during the one year delay. In addition, we estimate separate effects for children of different age groups in order to assess whether the retaining has heterogenous effects with respect to children's age.

Table 3 shows mean statistics of the repeating children in 2006 and 2007. Additionally, mean differences between non-recommended (repeating respectively) and recommended children in the two years are depicted. ${ }^{12}$ Comparing the means within the group of repeating children as shown in the first two columns of Table 3 shows that child and background variables are similar with exception of the time-varying variables age and time spent in child care which are larger due to the one year delay. The values on the developmental status indicate improvements in all four dimensions, e.g. the share of children with cognitive impairments decreases by 17 percentage points, from $50 \%$ of the non-recommended children in 2006 to $33 \%$ in 2007. Disorders in the health dimension are more persisting, so that the children attending the examination for a second time catch up by only 7 percentage points in this dimension.

The same improvement can be seen when looking at the mean difference to the recommended children as displayed in columns 3 and 4 of Table 3 . The positive difference, e.g. of 40 percentage points on cognitive impairments is the gap between non-recommended children, of whom $50 \%$ show cognitive impairments, and recommended children in 2006, where $10 \%$ show cognitive impairments (see Table 1). The differences for 2007 still being positive, albeit smaller, indicate that the developmental status of the group of repeaters improves but also that they are on average still more likely to show impairments than the the group of children they enter school with. Nevertheless, $99.4 \%$ of the repeaters are recommended for school.

\footnotetext{
${ }^{12}$ The differences presented in columns 3 and 4 of Table 3 result from subtracting the variable means of the children recommended in 2006 (2007) from the means of the non-recommended (repeating) children in the examination of 2006 (2007). The initial numbers for the difference in 2006 can be seen from the Table 1 in section 4.1 .
} 
Table 3: Mean values for repeaters and mean differences between repeaters and recommended children

\begin{tabular}{|c|c|c|c|c|}
\hline & \multicolumn{2}{|c|}{ Means } & \multicolumn{2}{|c|}{$\begin{array}{l}\text { Difference to } \\
\text { recommended children }\end{array}$} \\
\hline & $\begin{array}{r}\text { Non-rec. } \\
2006\end{array}$ & $\begin{array}{r}\text { Repeater } \\
2007\end{array}$ & $\begin{array}{r}\text { Non-rec. } \\
2006\end{array}$ & $\begin{array}{r}\text { Repeater } \\
2007\end{array}$ \\
\hline \multicolumn{5}{|l|}{ Child } \\
\hline Female & 0.36 & 0.36 & -0.13 & -0.12 \\
\hline Age (in months) & 67.49 & 79.23 & -4.52 & 8.78 \\
\hline Non-German mother tongue & 0.03 & 0.02 & 0.00 & 0.00 \\
\hline Birth Weight (in kg) & 3.24 & 3.24 & -0.15 & -0.14 \\
\hline Child care $>3$ years & 0.47 & 0.77 & -0.20 & 0.15 \\
\hline Early attendee & 0.18 & 0.00 & 0.12 & -0.07 \\
\hline Late attendee & 0.00 & 0.85 & -0.13 & 0.84 \\
\hline \multicolumn{5}{|l|}{ Developmental impairments } \\
\hline Cognitive development & 0.50 & 0.33 & 0.40 & 0.18 \\
\hline Socio-emotional development & 0.34 & 0.19 & 0.26 & 0.09 \\
\hline Motor development & 0.44 & 0.24 & 0.32 & 0.07 \\
\hline Health & 0.52 & 0.45 & 0.13 & 0.07 \\
\hline \multicolumn{5}{|l|}{ Background } \\
\hline Low SES & 0.30 & 0.29 & 0.12 & 0.13 \\
\hline Medium SES & 0.48 & 0.53 & -0.06 & 0.03 \\
\hline High SES & 0.16 & 0.16 & -0.09 & -0.11 \\
\hline Single Parent & 0.20 & 0.20 & 0.04 & 0.03 \\
\hline Siblings & 0.67 & 0.68 & 0.02 & 0.03 \\
\hline$N$ & 1,970 & 1,970 & $\begin{array}{r}20,717 \\
1,970\end{array}$ & $\begin{array}{r}19,132 \\
1,970\end{array}$ \\
\hline
\end{tabular}

Data Source: Health Ministry of Brandenburg 2006 and 2007. The number of observations for recommended children in columns 3 and 4 at the bottom of the table is the total number without missings. The following variables have missings: Non-German mother tongue, birth weight, child care, social status, single parent and number of siblings. The maximum share of missing values in 2006 (2007) amounts to $3.9 \%$ (6.6\%) for the recommended and $6.7 \%(8.8 \%)$ for the non-recommended (repeating) children.

The multivariate results presented in Table 4 confirm the mean comparisons. Nonrecommended children catch up in all screening dimensions by delaying school entry if compared to the reference group of non-repeating, recommended children in 2006. Children who are not recommended in 2006 have, given all other characteristics, a 39.0\% higher prevalence of cognitive development impairments than recommended children. This rate drops for the repeaters in 2007 to $11.4 \%$. But, although they delayed school entry and are above the age average now, they still show development impairments with a significantly higher probability than a average non-repeating, recommended child in 2006. The same holds for the other three developmental dimensions, however children catch up to a lesser extent with respect to health. 
Table 4: Probit regression of developmental outcomes as dependent variable: Average partial effects for repeating children

\begin{tabular}{|c|c|c|c|c|}
\hline & Cognitive & $\begin{array}{l}\text { Socio- } \\
\text { emotional }\end{array}$ & Motor & Health \\
\hline \multicolumn{5}{|l|}{ All children } \\
\hline Non-recommended 2006 & $0.390 * * *$ & $0.261^{* * *}$ & $0.286 * * *$ & $0.122^{* * *}$ \\
\hline Repeater 2007 & $0.114^{* * *}$ & $0.055^{* * *}$ & $0.081^{* * *} *$ & $0.056^{* * *}$ \\
\hline \multicolumn{5}{|l|}{ Young children } \\
\hline Non-recommended 2006 & $0.279^{* * *}$ & $0.253^{* * *}$ & $0.226 * * *$ & $0.091^{* * *}$ \\
\hline Repeater 2007 & $0.096^{* * *}$ & $0.048^{* *}$ & $0.047^{* *}$ & $0.083^{* *}$ \\
\hline \multicolumn{5}{|l|}{ Middle-aged children } \\
\hline Non-recommended 2006 & $0.391^{* * *}$ & $0.267 * * *$ & $0.285 * * *$ & $0.120^{* * *}$ \\
\hline Repeater 2007 & $0.095^{* * *}$ & $0.043^{* *}$ & $0.077^{* * *} *$ & 0.022 \\
\hline \multicolumn{5}{|l|}{ Old children } \\
\hline Non-recommended 2006 & $0.527 * * *$ & $0.239 * * *$ & $0.367^{* * *}$ & $0.164^{* * *}$ \\
\hline Repeater 2007 & $0.302^{* * *}$ & $0.127^{* * *}$ & $0.284^{* * *}$ & $0.193^{* * *}$ \\
\hline \multicolumn{2}{|l|}{$N$} & \multicolumn{2}{|c|}{43,789} & \\
\hline \multicolumn{5}{|c|}{$\begin{array}{l}\text { Data Source: Health Ministry of Brandenburg } 2006 \text { and } 2007 . * / * * / * * \text { indicate significance } \\
\text { at the } 10 / 5 / 1 \text { percent level. Regression using the pooled sample of } 2006 \text { and } 2007 \text { and the } \\
\text { estimation as described in Equation } 3 \text {. The partial effects for the dummy variables "Non- } \\
\text { recommended } 2006 \text { " and "Repeater } 2007 \text { " are calculated as treatment effects on the treated, } \\
\text { i.e. they are averaged within the group of non-recommended children } 2006 \text { and Repeater } 2007 \text {, } \\
\text { respectively. Control Variables for children, parental background, month of examination and } \\
\text { missing dummies are included. Child controls include variables female, non-German mother } \\
\text { tongue, birth weight, child care duration longer than } 3 \text { years as well as dummies for early and } \\
\text { late attendees. Control variables on family background include dummies for socio-economic } \\
\text { status, single parenthood and siblings living in the household. The month of examination is } \\
\text { controlled for by dummy variables. Missing dummies are included to indicate observations } \\
\text { with missing values in one of the variables. Missings are set to zero (dummy variables) or to } \\
\text { the mean (continuous variables) and included in the regression. }\end{array}$} \\
\hline
\end{tabular}

In order to consider heterogenous results of delaying school with respect to children's age, we additionally calculate the risk of developmental disorders separately for three different age groups: The young children born after September 2000 who attend the first examination a year earlier than they would have to, the middle-aged children born between April and September 2000 and the old children born before April 2000. Looking at these age groups reveals that older non-recommended children have more often problems with cognitive development, motor development and health, while younger children only show developmental impairments with respect to the socio-emotional dimension more often. This reflects that young children are often hold back purely due to age and not because of developmental impairments.

One year later almost all age groups show fewer impairments in all screening dimensions. Only within the group of older children more health disorders are observed in 2007. Younger children seem to catch up to a larger extent than older children. With an exemption in the cognitive dimension where children in the oldest age group improve to an similar extent. It might be easier for the younger non-recommended children (who have fewer severe problems) to improve during the year. Delaying school entry should 
thus be combined with interventions and encouragement especially for children who are already relatively old in their school cohort.

Results of the second part of our analysis suggest that delaying school entry allows retained children to improve. Their developmental status remains below average but developmental gaps are closing at least to some extent during the one year delay. Furthermore, younger children seem to catch up more often. Regarding the literature on school entry age, our results also indicate that school entrance screenings can be a possibility to attenuate the disadvantages of fix cutoff dates for relatively young children by means of delaying school entry.

\section{Conclusion}

In this paper we use school entrance examination data to analyze how early gaps in age and development influence children's probability to be recommended for school and whether developmental gaps close by delaying school entry. This is important since the previous literature on school entry age has shown that a strict application of cut-off dates leads to inter-cohort differences in age which have large effects on school performance. Although not lasting, these effects might severely influence school trajectories.

Our results indicate that age and developmental status are important predictors for school recommendation. Impairments in cognitive, socio-emotional and motor development as well as health are negatively related to the probability to receive a school recommendation. Moreover, younger children are less likely to be recommended for school. This occurs for two reasons: First, they show developmental impairments more often. Second, they have a lower probability of being recommended per se. The probability to be recommended for school increases by 1.6 percentage points per month of age. The influence of age is of particular importance to the children who are born in months close to the cut-off month as they are always the youngest. By not recommending younger and developmentally disordered children the examination sets a minimum development requirement which mitigates the developmental gaps within a cohort. Thus, performance differences in school as described in the literature on school entry age could be attenuated by a entrance screening.

Delaying school entry allows children to improve with respect to developmental status. Especially the younger retained children catch up more often. This might be easier for them as a smaller fraction of non-recommended younger children shows development impairments in the first place. However, after the delay of one year the repeating children of all ages still show more developmental impairments than the average of the recommended 
children. Nevertheless, they are all recommended for school as it might be not possible to delay school entry for another year because they constantly grow older.

Our results show that pediatricians seem to be sensitive with regard to child age and tend to deny recommendation for very young children. They either anticipate the improvement of younger children or might want to place them into a more favorable age position in the cohort of the following year. School entrance screenings thus are a useful instrument in harmonizing school entrance cohorts with respect to age and developmental differences.

While cutoff rules determine school entry by age, entrance examinations consider also a child's developmental status. In general, flexible school entry rules that - besides age - also take childrens' development into account could mitigate the disadvantages for relatively young children described by the literature on school entry age. 


\section{References}

Ai, C. \& Norton, E. C. (2003), 'Interaction terms in logit and probit models', Economics Letters 80(1), 123-129.

Angermaier, M. (1974), Psycholinguistischer Entwicklungstest (PET), Beltz Test, Weinheim.

Bedard, K. \& Dhuey, E. (2006), 'The persistence of early childhood maturity: international evidence of long-run age effects', Quarterly Journal of Economics 121(4), 14371472.

Bejerot, S. \& Humble, M. (2007), 'Relevance of motor skill problems in victims of bullying', Pediatrics 120(5), 1226-1227.

Böhm, A., Ellsäßer, G. \& Lüdecke, K. (2007), 'Der Brandenburger Sozialindex: ein Werkzeug för die Gesundheits- und Sozialberichterstattung auf Landes- und kommunaler Ebene bei der Analyse von Einschülerdaten', Gesundheitswesen 69(10), 555-559.

Burgemeister, B., Blum, H. \& Lorge, I. (1972), The Columbia Mental Maturity Scale, TX: Psychological Corporation, San Antonio.

Crawford, C., Dearden, L. \& Meghir, C. (2007), When you are born matters: The impact of date of birth on child cognitive outcomes in england, Research paper, Centre for the Economics of Education, London School of Economics.

Datar, A. (2006), 'Does delaying kindergarten entrance age give children a head start?', Economics of Education Review 25(1), 43-62.

Doherty, G., Friendly, M. \& Forer, B. (2002), Child Care by Default or Design? An Exploration of Differences Between Non-Profit and For-Profit Canadian Child Care Centres Using the You Bet I Care! Data Sets, Research paper, Childcare Resource and Research Unit, Centre for Urban and Community Studies, Toronto, Canada.

Elder, T. E. \& Lubotsky, D. H. (2009), 'Kindergarten entrance age and children's achievement. impacts of state policies, family background, and peers', Journal of Human Resources 44(3), 641-683.

Esser, G., Blanz, B., Geisel, B. \& Laucht, M. (1989), Mannheimer Elterninterview (MEI) - Strukturiertes Interview zur Erfassung von kinderpsychiatrischen Auffälligkeiten, Beltz Test, Weinheim.

Esser, G. \& Schlack, H. G. (2009), Umschriebene Entwicklungsstörungen, in H. G. Schlack, U. Thyen \& R. v. Kries, eds, 'Sozialpädiatrie. Gesundheitswissenschaft und pädiatrischer Alltag', Springer, Berlin, Heidelberg, pp. 157-187.

Esser, G. \& Wyschkon, A. (2000), Umschriebene Entwicklungsstörungen, in F. Petermann, ed., 'Lehrbuch der Klinischen Kinderpsychologie und -psychotherapie', Hogrefe, Göttingen, pp. 409-429.

Esser, G. \& Wyschkon, A. (2002), Basisdiagnostik für umschriebene Entwicklungsstörungen im Vorschulalter (BUEVA), Beltz Test, Göttingen. 
Garber, R. F., Timko, G., Bunkley, L. S., Lumpkins, D. \& Duckens, C. (2007), School Readiness Assessment: A Review of the Literature, Report, Community Research Partners and Franklin County Department of Jobs and Family Services.

Landesgesundheitsamt Brandenburg (2008), 'Handbuch für den Kinder- und Jugendgesundheitsdienst im Land Brandenburg. Leitlinien zur einheitlichen Durchführung und Dokumentation der kinder- und jugendärztlichen Untersuchungen', May 2008.

Landesinstitut für Gesundheit und Arbeit des Landes Nordrhein-Westfalen (2008), 'Jahresbericht 2006. Schulärztliche Untersuchungen in Nordrhein-Westfalen'.

Mayr, T. (1990), 'Zur Epidemiologie von Sprach-, Sprech- und Kommunikationsstörungen bei Vorschulkindern: Ergebnisse einer Screening-Untersuchung', Heilpädagogische Forschung 16(1), 14-20.

Möhring, H. (1939), 'Die Lautbildungsschwierigkeit im Deutschen', Zeitschrift für Kinderforschung 47, 205-227.

Puhani, P. A. \& Mühlenweg, A. M. (2010), 'The evolution of the school entry age effect in a school tracking system', Journal of Human Resources 45(2), 407-438.

Salm, M. \& Schunk, D. (2008), The role of childhood health for the intergenerational transmission of human capital: Evidence from administrative data, Working Paper 3646, Institute for the Study of Labor.

Simeonsson, R. J., Leonardi, M., Lollar, D., Bjorck-Akesson, E., Hollenweger, J. \& Martinuzzi, A. (2003), 'Applying the International Classification of Functioning, Disability and Health (ICF) to measure childhood disability', Disability \& Rehabilitation 25(11), 602610 .

Stedron, J. M. (2009), State Approaches to School Readiness Assessment, NCSL Technical Report, National Conference of State Legislatures.

Üstün, T. B., Chatterji, S., Kostansjek, N. \& Bickenbach, J. (2003), 'Who's icf and functional status information in health records', Health care financing review 24(3), 77 88 . 


\section{A Appendix}

\section{A.1 School entrance examination in Brandenburg}

The school entrance examination in Brandenburg is based on a core set of indictors of the International Classification of Functioning, Disability and Health (ICF) developed by the World Health Organization (WHO). Information on body and mental health of the child is obtained from observation of the pediatrician, interviews with parents and child as well as medical assessments. Qualifiers are used to indicate the degree of an impairment in three levels - mild, moderate and severe (Landesgesundheitsamt Brandenburg 2008).

The examination serves as a check-up for age adequate physical and psychological development. For the estimations, we use indicators on developmental status with regard to cognitive abilities, socio-emotional wellbeing, motor skills and health. All of the four dimensions are measured using several sub-tests which are in the following described in more detail.

The assessment of cognitive development includes measures for:

- articulation

- expressive language

- receptive language

- general intelligence

Cognitive development is measured using four subtests of the "Basisdiagnostik für umschriebene Entwicklungsstörungen im Vorschulalter", (BUEVA, Esser \& Wyschkon 2002) to detect developmental language disorders. The subtests include an articulation test (Möhring (1939)) and a grammar test for expressive language (PET, Angermaier 1974). For children who are affected by a disorder of speech and language according to these two further tests are administered, one on expressive language disorders (PET, Angermaier 1974) and one on general intelligence (Columbia Mental Maturity Scale, CMM, Burgemeister et al. 1972). The last one is a nonverbal test and can be used for children who showed difficulties with speech and language.

The assessment of socio-emotional development includes measures for:

- anxiety disorder

- anti social behavior

- attention deficit hyperactivity disorder (ADHD)

- enuresis

Psychiatric disorders in socio-emotional development are screened using questions from the "Mannheimer Elterninterview" (MEI, Esser et al. 1989). The assessment includes measures for anxiety, anti social (i.e. aggressive) behavior, attention deficit hyperactivity disorder (ADHD) and enuresis. The questions used for diagnosis are displayed in Figure A.1.1.

The assessment of motor development includes measures for gross motor skills to assess:

- power

- coordination,

- dynamic and static balance 
Figure A.1.1: Measures of psychiatric disorders in socio-emotional development

\begin{tabular}{|c|c|c|c|}
\hline My child... & Agree & Disagree & $\begin{array}{c}\text { Classification by federal } \\
\text { health office }\end{array}$ \\
\hline $\begin{array}{l}\text { gets distracted easily while playing at home } \\
\text { gets distracted easily at the nursery } \\
\text { is very restive and fidgety and can't sit still at home } \\
\text { (e. g. while eating) }\end{array}$ & ○ & $\circ$ & $\begin{array}{l}\text { ADHD: } \\
\text { agreed to both items of "at } \\
\text { home" or "at the nursery" } \\
\rightarrow \text { ADHD }\end{array}$ \\
\hline is very restive and fidgety and can't sit still at the nursery & 0 & 0 & \\
\hline $\begin{array}{l}\text { is often not following directions at home } \\
\text { is often not following directions at the nursery } \\
\text { is often involved in fights with other children }\end{array}$ & ० & $\circ$ & $\begin{array}{l}\text { Anti social behavior: } \\
2 \text { of } 3 \text { items agreed } \\
\rightarrow \text { affective-social } \\
\text { disorder }\end{array}$ \\
\hline $\begin{array}{l}\text { is often joshed, teased or beaten by other children } \\
\text { is afraid of other children }\end{array}$ & ० & ० & $\begin{array}{l}\text { Anxiety disorder: } \\
\text { both items agreed } \\
\rightarrow \text { affective-social } \\
\text { disorder }\end{array}$ \\
\hline wets the bed at least once a week & ० & 0 & $\begin{array}{l}\text { Enuresis: } \\
\text { agreed } \\
\rightarrow \text { enuresis }\end{array}$ \\
\hline
\end{tabular}

Source: Landesgesundheitsamt Brandenburg (2008).

Motor impairments are assessed using tests on gross motor skills. The development of motor functions is important for the overall development of perception and cognition. Although there seems to be no systematic relationship to later school performance (Esser \& Schlack 2009, Esser \& Wyschkon 2000), motor skill problems and poor performance in physical education might put these children at higher risk for becoming bullied (Bejerot \& Humble 2007). Tests used include standing and jumping on one leg as well as to walk in a straight line using tandem gait (heel-to-toe-walking).

The assessment of body health includes the following domains:

- sex, age in months

- height, weight, BMI

- allergies and asthma

- musculoskeletal system

- endocrine system

- hearing and seeing

- skin

The sub-tests used are described in a handbook which is available to all of the government pediatricians who administer the examination(Landesgesundheitsamt Brandenburg 2008). The results are collected in a standard form and completed by the information on family background variables. These include:

- parental education and labor force participation

- mother tongue of the child

- number of children in household

- number of adults in household

- duration of child care participation 


\section{A.2 Tables and Figures}

Table A.2.1: Average partial effects for the control variables not displayed in Table 2 (2006)

\begin{tabular}{|c|c|c|c|c|c|c|}
\hline & \multicolumn{6}{|c|}{ Average partial effects } \\
\hline & (I) & (II) & (III) & $(\mathrm{IV})$ & $(\mathrm{V})$ & $(\mathrm{VI})$ \\
\hline \multicolumn{7}{|l|}{ Child Controls } \\
\hline Female & $0.051^{* * *}$ & $0.022^{* * *}$ & $0.022^{* * *}$ & $0.021^{* * *}$ & $0.022^{* * *}$ & $0.022^{* * *}$ \\
\hline Non-German & 0.002 & -0.017 & -0.017 & -0.016 & -0.017 & -0.017 \\
\hline Birth Weight (in kg) & $0.033^{* * *}$ & $0.021^{* * *}$ & $0.021^{* * *}$ & $0.021^{* * *}$ & $0.021^{* * *}$ & $0.021 * * *$ \\
\hline Child care $>3$ years & $0.029 * * *$ & $0.022^{* * *}$ & $0.022^{* * *}$ & $0.021^{* * *}$ & $0.022^{* * *}$ & $0.022^{* * *}$ \\
\hline Early attendee & $0.014^{* *}$ & $0.010^{*}$ & $0.009^{*}$ & 0.007 & $0.009^{*}$ & $0.009^{*}$ \\
\hline Late attendee & $0.027^{*}$ & $0.045^{* * *}$ & $0.043^{* * *}$ & $0.034^{* * *}$ & $0.044^{* * *}$ & $0.044^{* * *}$ \\
\hline \multicolumn{7}{|l|}{ Family Background } \\
\hline Medium SES & $0.051 * * *$ & $0.015^{* * *}$ & $0.015^{* * *}$ & $0.015^{* * *}$ & $0.015^{* * *}$ & $0.015^{* * *}$ \\
\hline High SES & $0.077^{* * *}$ & $0.036^{* * *}$ & $0.036^{* * *}$ & $0.036^{* * *}$ & $0.036^{* * *}$ & $0.036^{* * *}$ \\
\hline Single Parent & 0.003 & 0.005 & 0.006 & 0.006 & 0.005 & 0.005 \\
\hline Siblings & $-0.011^{* * *}$ & -0.002 & -0.002 & -0.002 & -0.002 & -0.002 \\
\hline \multicolumn{7}{|l|}{ Month Dummies } \\
\hline January (and before) & -0.006 & $0.017^{* * *}$ & $0.017^{* * *}$ & $0.016^{* * *}$ & $0.017^{* * *}$ & $0.017^{* * *}$ \\
\hline February & 0.004 & $0.011^{* * *}$ & $0.011^{* * *}$ & $0.011^{* * *}$ & $0.011^{* * *}$ & $0.011^{* * *}$ \\
\hline April & $-0.023^{* * *}$ & $-0.022^{* * *}$ & $-0.022^{* * *}$ & $-0.022^{* * *}$ & $-0.022^{* * *}$ & $-0.022^{* * *}$ \\
\hline May (and after) & $-0.074 * * *$ & $-0.058^{* * *}$ & $-0.058^{* * *}$ & $-0.057^{* * *}$ & $-0.058 * * *$ & $-0.058 * * *$ \\
\hline \multicolumn{7}{|l|}{ Missing Dummies } \\
\hline Mother-tongue & $-0.042^{* * *}$ & $-0.024^{* *}$ & $-0.024^{* *}$ & $-0.024^{* *}$ & $-0.024^{* *}$ & $-0.024^{* *}$ \\
\hline Birth weight & $-0.046^{* * *}$ & $-0.023^{* * *}$ & $-0.023^{* * *}$ & $-0.023^{* * *}$ & $-0.023^{* * *}$ & $-0.023^{* * *}$ \\
\hline Child care & $0.014^{*}$ & 0.009 & 0.009 & 0.009 & 0.009 & 0.009 \\
\hline Siblings & -0.072 & -0.032 & -0.032 & -0.033 & -0.032 & -0.032 \\
\hline Parental situation & $0.045^{*}$ & 0.019 & 0.019 & 0.019 & 0.019 & 0.019 \\
\hline SES & 0.009 & 0.006 & 0.006 & 0.005 & 0.006 & 0.006 \\
\hline
\end{tabular}

Data Source: Health Ministry of Brandenburg 2006. */**/*** indicates significance at the 10/5/1 percent level. NonGerman refers to non-German mother tongue. The examination is predominantly taken from January to April, however there are very few children tested in the months June to December. The control variable for month January thus includes also the months October, November, December. The variable for month May includes also the months June, July, August and September. Reference category is March as this is the month where most examinations are taken. 
Table A.2.2: Means for total and recommended cohort

\begin{tabular}{lrrrrr}
\hline \multirow{2}{*}{ Variable } & & \multicolumn{2}{c}{ Mean } & \multicolumn{2}{c}{ t-test } \\
Female & Sample & Treated & Control & $\mathrm{t}$ & $p>|t|$ \\
Year of birth & Unmatched & 0.356 & 0.363 & -0.420 & 0.677 \\
& Matched & 0.356 & 0.363 & -0.430 & 0.666 \\
Month of birth & Unmatched & 2000 & 2000 & -1.010 & 0.312 \\
& Matched & 2000 & 2000 & -0.520 & 0.600 \\
Non-German & Unmatched & 7.590 & 7.634 & -0.590 & 0.555 \\
\multirow{3}{*}{ Birth weight } & Matched & 7.590 & 7.567 & 0.300 & 0.764 \\
& Unmatched & 0.027 & 0.020 & 1.500 & 0.134 \\
Maternal school education & Matched & 0.027 & 0.021 & 1.140 & 0.253 \\
Single parenthood & Unmatched & 3.238 & 3.258 & -0.980 & 0.325 \\
& Matched & 3.238 & 3.236 & 0.130 & 0.895 \\
Siblings & Matched & 2.129 & 1.990 & 6.750 & 0.000 \\
& Unmatched & 0.129 & 2.000 & 6.100 & 0.000 \\
& Matched & 0.203 & 0.213 & -0.810 & 0.415 \\
& Matched & 0.673 & 0.680 & -0.120 & 0.905 \\
& Unmatched & 0.673 & 0.678 & -0.340 & 0.618 \\
\hline
\end{tabular}

Data Source: Health Ministry of Brandenburg 2006 and 2007.

Figure A.2.1: Area of common support in nearest neighbor matching

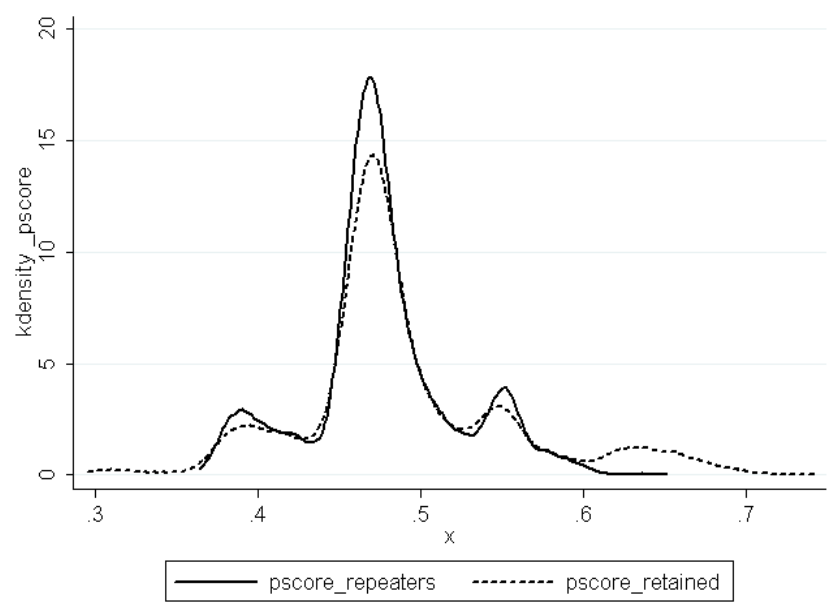

Data Source: Health Ministry of Brandenburg 2006 and 2007. 